Available Online : https://proceeding.researchsynergypress.com/index.php/cset/index

RSF Conference Series: Engineering and Technology

ISSN 2809-6843 (Online) | 2809-6878 (Print)

Volume 1 Number 1 (2021): 494-499

\title{
Modification Model of Soil Fertility Evaluation FAO-UNESCO on the Slopes of Merapi Volcano, Indonesia
}

\author{
E. A. Julianto' , Partoyo $^{2}$, Sri Suharsih ${ }^{3}$ \\ 1,2 Department of Agrotechnology, UPN “Veteran” Yogyakarta, Indonesia \\ ${ }^{3}$ Faculty of Economic and Business, UPN “Veteran" Yogyakarta, Indonesia
}

\begin{abstract}
One of the mountains known as active volcanoes in the world was Merapi volcano. From the very active impact of Merapi activity, there was a continuous addition of volcanic material associated with soil fertility, which can be evaluated using the Soil Fertility Evaluation (SFE) system. This study aims to obtain a more adaptive SFE system to the southern slopes of Merapi volcano by modifying the FAO- UNESCO version of SFE system that still uses linear equations. In this research used system of quadratic equation, use of natural logarithm (ln), and modification of new parameter. From the evaluation of soil fertility is then connected with the production component of paddy rice (dry grains crop). There were several indicators that used to see the quality of the model or test the goodness of fit of the model we make, for example from its R2. In this study the quality of a model was seen from: Akaike Info Criterion (AIC) and Schwarz Criterion (SC), and the data was done by using EViews 9. The results showed the parameters that influence big in the model can be seen from the correlation and influence the parameters in single. Quadratic equations can improve the quality of a model over a linear equation. The standard SFE model which is modified by using the natural logarithm (ln) and the contribution of new parameters can improve the quality of the model.
\end{abstract}

Keywords: Soil fertility evaluation, Modification model, Akaike info criterion, Schwarz criterion, Merapi volcano

\section{INTRODUCTION}

The choice of an evaluation method that is highly correlated with plant productivity is a rational step for efficiency and effectiveness in the planning of soil fertility management. The results of the fertilizing procedure based on the national recommendation are still unsatisfactory. The inadequacy of the present SFE system for the southern slopes of Merapi volcano necessitates an alternative SFE system/ modification that is more adaptive to the southern slopes of Merapi volcano.

The soil fertility evaluation to be evaluated is the FAO-UNESCO version of SFE. The advantage of the FAOUNESCO version of SFE system is that the number of parameters involved is not much and the disadvantage is that the equation used is a linear equation. Some parameters use soil fertility parameters that are in total in the soil. The use of parameters in logarithmic form. There are nine fertility parameters used in this FAO-UNESCO system. The application of FAO- UNESCO system model on the southern slopes of Merapi volcano in Yogyakarta, Indonesia is low effectiveness. This is indicated by the small value of R2. On that basis, the researcher has thought to increase the effectiveness of FAO-UNESCO system model by:

replace the existing SFE parameters with the new parameter, (b) added an existing SFE parameter with the new parameter, (c) squares parameters independently of great significance (quadratic equations), and (d) regression is done with the same Y, namely Dry Grains Crop (DGC) with X in the form of soil fertility parameters. The researcher's expectation by modifying the model of FAO-UNESCO system with these steps is finding the model that has higher effectiveness (the model is getting stronger/valid). 
There are several indicators used to ensure the good quality of a model. In the language of statistics, it is to test the goodness of fit a model that we make. The quality of a model can be seen from $\mathrm{R}^{2}$, Akaike Info Criterion (AIC) and Schwarz Criterion (SC). Research on SFE using AIC and SC and EViews 9 is limited. It is hoped that this research will produce a better-quality model than the existing model. The objective of this research is therefore to obtain an SFE that is more suited to the southern slopes of Merapi Volcano.

\section{LITERATURE REVIEW}

Any input to a farming operation aims to improve the welfare of a farming community. The highly active Merapi volcano causes persistently increased volcanic materials; therefore, there is a need for an adaptive system of Soil Fertility Evaluation (SFE).

Studies showed that rice productivity was strongly influenced by soil texture, nutrient concentration and organic matter (Aminuddin et al. 2003). Paddy soils are naturally heterogeneous. Complex interrelationships exist between physical, chemical, and biological soil properties have long been recognised. Their responses along with management-induced soil changes like tillage, liming and fertiliser amendments result in soil variation within cropped fields (Baucer and Black 1994; Olson et al. 1996; Gardner and Clancy 1996) and thus, as a surrogate measure of more costly soil chemical and physical measurements that directly affect plant growth and yield (Jaynes 1996).

Efficient and effective soil fertility management planning can be obtained by choosing an evaluation method that has a high correlation with crop productivity. The results of the fertilizing procedure based on the national recommendation are still unsatisfactory. The inadequacy of the present SFE system for the southern slopes of Merapi volcano necessitates an alternative SFE system/ modification that is more adaptive to the southern slopes of Merapi volcano.

The soil fertility evaluation to be evaluated is the FAO-UNESCO version of SFE. The advantage of the FAOUNESCO version of SFE system is that the number of parameters involved is not much and the disadvantage is that the equation used is a linear equation. Some parameters use soil fertility parameters that are in total in the soil. The use of parameters in logarithmic form. There are nine fertility parameters used in this FAO-UNESCO system. The application of FAO- UNESCO system model on the southern slopes of Merapi volcano in Yogyakarta, Indonesia is low effectiveness. This is indicated by the small value of R2. On that basis, the researcher has thought to increase the effectiveness of FAO-UNESCO system model by: (a) replace the existing SFE parameters with the new parameter, added an existing SFE parameter with the new parameter, (c) squares parameters independently of great significance (quadratic equations), and (d) regression is done with the same Y, namely Dry Grains Crop (DGC) with X in the form of soil fertility parameters. The researcher's expectation by modifying the model of FAO-UNESCO system with these steps is finding the model that has higher effectiveness (the model is getting stronger/valid).

The suitability and quality of a model can be approached by several related indicators. The quality of a model can be seen from $\mathrm{R}^{2}$, Akaike Info Criterion (AIC) and Schwarz Criterion (SC). Research on SFE using AIC and SC and EViews 9 is limited. It is hoped that this research will produce a better-quality model than the existing model. The objective of this research is therefore to obtain an SFE that is more suited to the southern slopes of Merapi Volcano.

\section{RESEARCH METHODOLOGY}

The research site is located on the southern slopes of Mount Merapi, which is one of the most active volcanoes in the world. Lowland rice cultivation is the commodity of choice because the area is a food buffer in the DIY province. Determination of the point using stratified purposive sampling, by determining the places that are still planted with lowland rice as many as 37 points. Some of the parameters observed in this study were: C-org, N-total, pH H2O, pH KC1, P2O5, K2O, P-Bray, Morgan $\mathrm{K} 2 \mathrm{O}, \mathrm{Ca}, \mathrm{Mg}, \mathrm{K}, \mathrm{Na}$, Ca-total, Mg-total, Cation Exchange Capacity (CEC), Si, Texture, Base Saturation, P 
Retention, and P-Olsen. The observed crop production was dry milled grain (DGC).

The standard FAO-UNESCO system model is: DGC $=\log \mathrm{KPK} \times((\log \mathrm{C}$ org $+\log \mathrm{K}$-dd (available) $+\log$ $\mathrm{P}$ tsd (olsen $\mathrm{P} 205)+\log$ retention $\mathrm{P})+(\mathrm{Ca} 1 \log (\mathrm{HCl} 25 \%)+\log \mathrm{Mg} 1(\mathrm{HCl} 25 \%+\log \mathrm{K} 20(25 \% \mathrm{HCl}+$ $\log \mathrm{P} 2 \mathrm{O} 5$ ( $\mathrm{HCl} 25 \%)$ ) In the standard model will be modified. In this modification is used Econometric Views (Eviews) 9 statistical data processor. EViews 9 is a modern econometric, statistics, and forecasting package that offers powerful analytical tools within a flexible, easy-to-use interface.

Analysis was done on regression and the correlation of the soil fertility parameters with plant production (DGC). Regression was done in a single and multiple manner. The methods used to obtain a quality model (goodness of fit) were as follows: (a) Replacing the existing SFE parameters with new parameters. (b) Adding the existing SFE parameters with new parameters. (c) Using natural logarithm (ln) in its operation. (d) Making quadratic the parameters that separately had substantial significance (i.e. quadratic equation). (e) Regression was done with the same Y, i.e. DGC with X in the form of soil fertility parameters.

By using EViews 9 as a statistical data processor, the indicators of a good quality model can be seen from $\mathrm{R}^{2}$, Akaike Info Criterion (AIC) and Schwarz Criterion (SC) indicators. A high $\mathrm{R}^{2}$ does not always indicates that the quality of a model is good. In a time series analysis, in which all variables undergo an increase with the passage of time, the $\mathrm{R}^{2}$ value tends to be high. In data cross section analysis, the $\mathrm{R}^{2}$ value tends to be low. To assess the quality of a model, the following formula can be used:

$$
\begin{aligned}
& \mathrm{AIC}=\log \left[\sum \mathrm{e} 1^{\wedge} 2 / \mathrm{n}\right]+2 \mathrm{k} / \mathrm{n} \text { Where: } \\
& \begin{array}{ll}
\sum \mathrm{e} 1^{\wedge} 2 & =\text { the residual quadrate } \\
\mathrm{K} & =\text { number of independent variables, } \\
\mathrm{n} & =\text { number of observations. }
\end{array}
\end{aligned}
$$

The smaller the AIC figure, the better the model, but this value can only be compared if there is another model whose AIC has been counted (Akaike 1974 andAkaike1978). In order to corroborate the assessment of the quality of a model, this formula can be used:

$$
\begin{aligned}
& \text { SIC }=\log \left[\sum \mathrm{e} 1^{\wedge} 2 / \mathrm{n}\right]+\mathrm{k} / \mathrm{n} \log \mathrm{n} \text { Where: } \\
& \sum \mathrm{e} 1^{\wedge} 2 \quad=\text { the residual quadrate, } \\
& \mathrm{K} \quad=\text { number of independent variables, } \\
& \mathrm{n} \quad=\text { number of observations. }
\end{aligned}
$$

The smaller the SIC, the better the model. Two quality models can be compared with each other using the SIC criteria. So the requirement for the two models is to calculate the SIC. The selection of this criterion is therefore widely used because of its computational simplicity and effectiveness in its performance in many modeling frameworks. The Bayesian posterior probability transformation of the candidate model is used as a criterion for the asymptotic approach (Schwarz, 1978)

\section{FINDING AND DISCUSSION}

\section{Correlation between the Soil Fertility Factor and the Wet field Rice Production}

The results of analysis on the correlation between the soil fertility factor (as an independent variable) and the rice production component/ DGC (as a dependent variable) shows that N, K2O, Pretention, total Mg, $\mathrm{Si}$ and $\mathrm{CaMg}$ are dominated by a not very tight correlation (insignificant) with the rice production (DGC). This is presented in Table 1. However, there are several parameters that are tightly correlated with the wet field rice production component/ DGC, namely C-org, P205, KB, K and Morgan K2O. The parameters that are very tightly correlated are the sand fractions, Bray 1, CEC and Ca-total. Among the nutrient 
availability in the soil, Bray1 has the tightest correlation $\left(r=0.79^{* *}\right)$ with rice production/ DGC, but on the other hand the pretention to the rice production component is the least insignificant $(r=0.01 \mathrm{~ns})$; this is due to the dominance of the sand fraction on the soil, so that the binding ability of $\mathrm{P}$ in organic matter and clay becomes very low. The parameters that have a tight and very tight relation with the DGC component will be used as a parameter to be made quadratic, involved in the use of natural logarithm (ln), and involved in the addition of new parameters for the modified SFE model.

Table 1 Correlation coefficient ( $\mathrm{r}$ ) of the soil fertility factor (soil chemical property) with wet field rice production/DGC $(\mathrm{n}=37)$.

\begin{tabular}{|c|c|c|c|c|c|c|c|c|c|c|c|c|c|c|c|}
\hline \multicolumn{3}{|c|}{ Parameter } & \multicolumn{13}{|c|}{ Correlation Coefficient } \\
\hline & SAND & CORG & $\mathrm{N}$ & $\mathrm{P} 2 \mathrm{O} 5$ & $\mathrm{~K} 20$ & BRAY1 & $\mathrm{KB}$ & CEC & $\mathrm{K}$ & $\begin{array}{c}\mathrm{P} \\
\text { RETENTI } \\
\text { ON } \\
\end{array}$ & $\begin{array}{c}\text { MORGAN } \\
\text { K2O }\end{array}$ & $\mathrm{CAl}$ & MG1 & S1 & CAMG \\
\hline DGC2 & $\left.0.65^{* *}\right)$ & $\left.0.48^{* *}\right)$ & $0.13 \mathrm{~ns}$ & $\left.0.38^{*}\right)$ & $-0.17 \mathrm{~ns}$ & $0.79 * *)$ & $\left.0.42^{* *}\right)$ & $\left.0.52^{* *}\right)$ & $\left.0.47^{* *}\right)$ & $\left.0.01^{* *}\right)$ & $\left.0.48^{* *}\right)$ & $\left.0.50^{* *}\right)$ & $0.13 \mathrm{~ns}$ & $0.27 \mathrm{~ns}$ & $-0,04 \mathrm{~ns}$ \\
\hline
\end{tabular}

Notes: $n s=$ insignificant; ${ }^{* *}=$ very significant at $\mathrm{p}<0,01{ }^{*}=$ significant at $\mathrm{p}<0,05$

\section{Influence of AIC and SIC of FAO SFE model and SFE modified model}

When we use the standard model of FAO, the regression coefficient $\left(R^{2}\right)$ will be smaller than that of the FAO modified model. Model modification can be done by making quadratic the parameters with high correlation with and/or great single influence (from analysis of variance) on plant production (DGC2). Addition/ replacement with new parameters can also increase $\mathrm{R}^{2}$. This can be seen (Table 2) in the standard FAO model, which makes a model with P total (P2O5 total) and K2O total; after the total parameters are replaced with P-available (PBray) and K- available with Morgan K20, this can increase $\mathrm{R}^{2}$ and lower AIC and SIC. This means that the model is stronger/ better. Likewise, natural logarithm (ln) has a greater influence than an ordinary logarithm because the divisor of a natural logarithm is smaller than that of an ordinary logarithm so that its value is close to the real value.

Table 2 AIC and SC of FAO standard model and modified model

\begin{tabular}{|c|c|c|c|c|}
\hline Evaluation method & R2 & AIC & SIC & $\begin{array}{l}\text { Prob } \\
\text { (F-statistic }\end{array}$ \\
\hline \multicolumn{5}{|l|}{$\overline{\text { FAO }}$} \\
\hline FAO Standard & 0.440 & 16.425 & 16.514 & 0.000019 \\
\hline \multicolumn{5}{|l|}{ Modified Model: } \\
\hline Eviews standard & 0.823 & 15.745 & 16.194 & 0.000000 \\
\hline Eviews standard and DGC2LOG & 0.852 & -3.678 & -3.243 & 0.000000 \\
\hline LOG(BRAY1) and LOG(MORGANK20) & 0.856 & 15.534 & 15.983 & 0.000000 \\
\hline \multicolumn{5}{|l|}{ DGC2LOG, LOG(BRAY1) and } \\
\hline LOG(MORGANK20) & 0.883 & -3.913 & -3.478 & 0.000000 \\
\hline $\mathrm{LOG}(\mathrm{CEC})^{\wedge 2}$ and $\mathrm{LOG}(\mathrm{CORG})^{\wedge 2}$ & 0.750 & 16.088 & 16.537 & 0.000022 \\
\hline $\begin{array}{l}\text { DGC2LOG } \\
\text { LOG(CORG) })^{\wedge}\end{array}$ and LOG(CEC $)^{\wedge 2}$ & 0.787 & -3.316 & -2.880 & 0.000001 \\
\hline \multicolumn{5}{|l|}{ NORMAL LOGARITHM (LN) } \\
\hline DGC2(LN) & 0.498 & -1.220 & -1.133 & 0.000001 \\
\hline Eviews standard & 0.851 & 15.568 & 16.017 & 0.000000 \\
\hline (LN)BRAY1 and (LN) MORGANK20 & 0.893 & 15.180 & 15.584 & \\
\hline DGC2(LN), $\quad$ (LN)BRAY1 & 0.899 & -2.393 & -1.957 & 0.000000 \\
\hline
\end{tabular}


RSF Conference Series: Engineering and Technology

Vol. 1 (1), 494-499

Modification Model of Soil Fertility Evaluation FAO-UNESCO on the Slopes of Merapi Volcano, Indonesia

E. A. Julianto, Partoyo, and Sri Suharsih

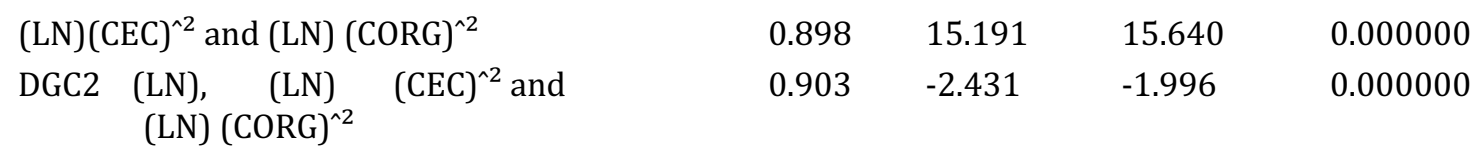

Table 2 also shows that by modification of the FAO model, the standard values of AIC and SIC in the FAO models tend to be greater than those of the modified model. This means that the modified model is stronger, as shown by the smaller AIC and SIC values. It can also be seen from Table 2 which of the modified FAO models is the strongest, i.e., by seeing the biggest $\mathrm{R}^{2}$, the smallest AIC, and the smallest SIC. This is consistent with the view of (Akaike 1974; Akaike 1978; Schwarz 1978; Stone 1979) that the smaller the AIC and SIC figures, the better the model, but this value can only be compared if there is another model whose AIC and SIC have been counted. In terms of its $\mathrm{R}^{2}$ the modified FAO, $\mathrm{R}^{2}=0.903$ whereas in the standard FAO $\mathrm{R}^{2}=0.82$. The equation as shown in Table 2 EViews standard is:

DGC2=-16098.05+1695.53*LOG(CEC)+1663.19*LOG(CORG)+

367.94*LOG(K)+323.07*LOG(OLSENP205)+513.78*LOG(P-

RETENTION)+1581.70*LOG(CA1)+940.08*LOG(MG1)-98.71*LOG(K20)+

306.29*LOG(P205) (1)

While equation in Table 2 modified model DGC2 (LN), (LN) (CEC) ${ }^{\wedge}$ and (LN) (CORG) ${ }^{\wedge}$ is: DGC2LN=3.37+0.001*(LN) $(\mathrm{CEC})^{\wedge} 2+0.11^{*}(\mathrm{LN})(\mathrm{CORG})^{\wedge} 2+1.27^{*}(\mathrm{LN}) \mathrm{K}+0.001^{*}(\mathrm{LN}) \mathrm{BRAY} 1-$ $0.0001^{*}(\mathrm{LN})$ RETENSIP+2.56e-05*(LN)CA1+0.0003*(LN)MG1- $0.0007^{*}(\mathrm{LN})$ MORGANK20 $+0.0004^{*}(\mathrm{LN}) \mathrm{P} 205$

Analysis of a model's quality by graphic approach

To confirm the above results, an analysis by using graphics is presented in Table 3 and

Figure 1. Table 3 Graphical approach in FAO model

\begin{tabular}{lllll}
\hline Evaluation method & R2 & AIC & SIC & Prob (F-statistic) \\
\hline $\begin{array}{l}\text { FAO } \\
\text { FAO standard (Figure 1 on the left.) }\end{array}$ & 0.440 & 16.425 & 16.514 & 0.000019 \\
\hline FAO standard by Eviews 9 & 0,823 & 15,745 & 16,194 & 0.000000 \\
\hline $\begin{array}{l}\text { DGC2 (LN) (CEC) })^{\wedge} \text { and (LN) } \\
\text { (CORG) }\end{array}$ & 0.903 & -2.431 & -1.996 & 0.000000 \\
\hline
\end{tabular}

Table 3 shows that, the higher the regression coefficient (R2) (0.903), the smaller the probability (F-

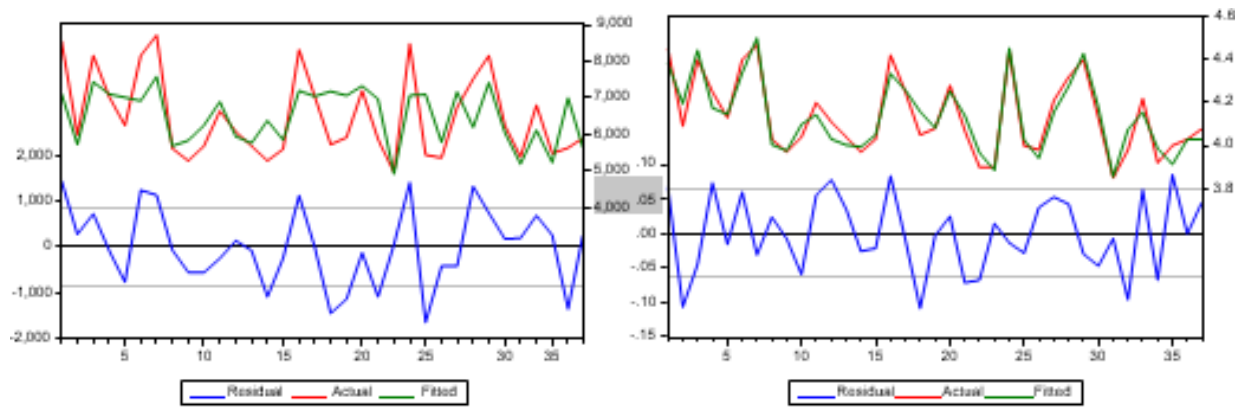

Figure $1 \mathrm{~A}$ model's quality using a graphical approach 
statistics) so that the significance is greater. Meanwhile, if the regression coefficient (R2) is getting lower (0.440), it will be followed by the greater the probability (F-statistics) so that the significance is getting smaller. This is corroborated by Figure 1, where the actual and fitted curves that coincide show that the model is of higher quality than those that are far apart, the distance of the curves that are far apart shows that there are still many factors that have not been included in the model.

\section{CONCLUSION AND FURTHER RESEARCH}

The model with the best quality is a model with a modified FAO natural logarithm with several additional parameters, i.e., CEC and quadratic C-organic.

DGC2LN $=3,366+0,001^{*}(\mathrm{LN})(\mathrm{CEC}) \wedge 2+0,105^{*}(\mathrm{LN})(\mathrm{CORG}) \wedge 2+1,265^{*}(\mathrm{LN}) \mathrm{K}+0,001^{*}(\mathrm{LN}) \mathrm{BRAY} 1-$ $0,0001^{*}(\mathrm{LN})$ P RETENTION +

2,555e-05*(LN)CA1 + 0,003*(LN)MG1 - 0,0007*(LN)MORGANK20 + $0,0004 *(\mathrm{LN}) \mathrm{P} 205$

Replacement of parameters in the total form in the FAO standard model to become an available model in the FAO modified model can improve the quality of the model. The use of a parameter in the form of log in the FAO standard model to become a natural logarithm (ln) in the FAO modified model can improve the quality of the model.

\section{Acknowledgement}

The authors would like to thank the Institute for Research and Community Service at Universitas Pembangunan Nasional Veteran Yogyakarta, Indonesia, for providing funds for this research.

\section{REFERENCES}

Akaike H. 1974. A new look at the statistical model identification. IEEE Transactions on Automatic Control 19: 716-23.

Akaike H. 1978. Time series analysis and control through parametric methods. In Applied Time Series Analysis, Edited by: Findley D. pp 1-24. Academic Press, New York.

Aminuddin B Y, Zulkafli I, AbdRazak H, Abdul Munir J and Abdul Rahim A. 2003. Mapping soil and nutrient variations for precise fertilizer management in rice farm. Poster paper, Modern rice farming, Alor Setar.

Baucer A and Black A L. 1994. Quantification of the effect of soil organic matter content on soil productivity. Soil Science Society of America Journal 58:185-93.

Cavanaugh J E, Neath A A and Shumway R H. 1995. A generalized derivation of the Schwarz information criterion University of Missouri Columbia Technical Report Department of Statistics, Missouri.

Gardner J C and Clancy S A. 1996. Impact of farming practices on soil quality in North Dakhoda. pp 337-43. In Doran J W and Jones A J (eds.) Methods for assessing soil quality. SSSA Spec. Publ. 49. SSSA, Madison, WI.

Jaynes D B. 1996. Improved soil mapping using electromagnetic induction surveys. pp 169-79, In Robert et al. (eds.) Proceeding International Conference on

Precision Agriculture, 3rd, Minneapolis, MN. 23-26 June 1996. ASA, CSSA, and SSSA, Madison, WI.

Julianto E A, Suntoro W A, Dewi W S and Partoyo. 2018. Graphical approach to assess the soil fertility evaluation model validity for rice (case study: Southern area of Merapi Mountain, Indonesia. IOP Conference Series: Earth and Environmental Science. pp 1-7. Surakarta.

Olson G L, McQuaid B G, Easterling K N and Scheyer J M. 1996. Quantifying soil conditionand productivity in Nebraska. pp 357-69. In Doran J W and Jones A J (eds.) Methods for assessing soil quality. SSSA Spec. Publ. 49. SSSA, Madison, WI.

Schwarz G. 1978. Estimating the dimension of a model. The Annals of Statistic 6: 461-4.

Stone M. 1979. Comments on model selection criteria of Akaike and Schwarz. Journal of the RoyalStatistical Society, B 41: 276-8 